\title{
Netnography: towards a new sociological approach of qualitative research in the digital age
}

\author{
Mahjouba Kaoukaou ${ }^{1 *}$
}

${ }^{1}$ CRMEF, Regional Center For Education And Training Professions- Rabat-Kénitra, Morocco

\begin{abstract}
This paper tackles the question of netnography in the digital age. The shifts that the world has known during these last decades lead to the emergence of a new paradigm. The research in digital studies raises today many issues about the notions and the methods that we should use in this new field of study. We aim from our research to contribute to this current scientific discussion through a main question that we intend to address in our paper, and which we can formulate as follows: what is the nature of the criteria and the characteristics which make netnography a different method than ethnography? And if the subject of study in this practice is virtual and geographically undetermined, how can the researcher limit it, and how can he address it scientifically? Our goal from this paper is to unveil the specificity of netnography as a new notion and a new practice in sociology. So, we will formulate our perception of this concept by demarcating the lines between it and the other notions which intersect with it, namely, ethnography.
\end{abstract}

\section{General framing of the research subject}

Observation is one of the leading technic used in sociological research. The most important sociological works were formulated upon the written notes that sociologists gathered from the field through long-term observation of the communities that they lived in during a period of time. That is why ethnography was, and still is, a common method in sociological research. This means that any given definition of this method supposes two elements: community and the written description produced about it.

Thus, scholar's concern may go to one side or more (institution, small groups, etc.) in a particular community, which could constitute the subject of his description; or that concern may go to the society, in general, which makes the research more holistic. Given these points, we can say that the social manifestations and components expressed and produced amid a society, as a result of activities and interactions of individuals, could be a subject of ethnographic observation.

Accordingly, ethnography is defined, in this context, as "the study of social interactions, behaviours, and perceptions that occur within groups, teams, organizations, and communities $\gg\left[{ }^{1}\right]$. It is a qualitative method by which the researchers aim to understand the different sides and manifestations of human social life through close observation of its fine details.

It is evident that the communities which we refer to, in the previous definition, are the physical ones, namely those entities which are located in geographical places; and which are inhabited by definite individuals who are themselves identified by real identities (in a

\footnotetext{
* Corresponding author: hajibakaoukaou@email.com
} 
physical and a symbolic sense). This type of community has long been the subject of study since the emergence of sociology as a scientific field. But the significant shift that our world has known during these recent decades, because of modern technology, has affected our societies deeply in many ways.

All the manifestations of social life were subjected to extreme changes due to the digital revolution: the nature and structure of communities, the ways how we live in them, and how we express ourselves, the types of human activities and interactions, the forms of identities, and how we display them, and so forth. Each component of our daily life has been a part of this unprecedented shift.

Henceforth, a new paradigm has emerged in the field of social science to embrace all these changes. The scholars start to use new notions to depict this novel reality, such as virtual community $\left[{ }^{2}\right]$, digital generation $\left[{ }^{3}\right]$, virtual relationships $\left[{ }^{4}\right]$ and so forth. Similarly, this change in the conceptual system was accompanied by a shift in the methodology employed in studying digital communities.

Nowadays, we notice that scholars utilize many concepts to define the specific methodology that they use to study the virtual society and to distinguish it from the classical methods which are commonly used in social research. In this context, « digital methods » $\left[{ }^{5}\right]$, and «virtual methods " $\left[^{6}\right]$ emerged as new concepts which refer to all technics and tools employed by researchers in their studies of internet uses. The netnography was one of these new methods.

\section{Research questions}

So if some scholars distinguish, in general, between virtual methods, digital method, and methods as-usual $\left[^{7}\right]$ to reflect the specificity of the digital studies, the same distinction also applies to ethnography comparing to netnography. The first one is considered currently by some scholars as a traditional method $\left[^{8}\right]$; it falls under the methods as-usual, whereas the second fulls within the virtual methods. But the questions raise here are: what is the nature of the criteria and the characteristics which make netnography a different method than ethnography? And if the subject of study in this practice is virtual and geographically undetermined, how can the researcher limit it, and how can he address it scientifically; this taking into account that one of the sines qua non-condition of sociological study is to define and narrow the scope of study?

\section{Research objectives}

This paper aims to unveil the specificity of netnography through a review of its most important properties. Netnography, like other methods, has its pro and con. Therefore, the researchers in digital studies need currently to know the opportunities which netnography gives to them to invest it properly to grasp the new issues and phenomenons that emerge during the recent decades because of the internet uses in contemporary life. And they also need to be aware of the problems and the constraints that this method arises, to cope with it adequately in their research. Although netnography as a method had been employed practically since the beginning of the 1990s with many American researchers like Sherry Turkle and Sandy Stone, the notion was not created until the mid of 1990s by Robert Kozinets in the domain of marketing. 
Therefore, netnography had not been developed, theoretically and methodically, and had not become broadly used by western scholars until recent years. In contrast, netnography, in other countries, namely the Middle East and the Maghreb countries, is still considered as a new concept, and a new practice that has not yet been explored or invested. So, taking into consideration that the "digital ethnographic methods" are still perceived as "emergent" methods $\left[{ }^{9}\right]$, the importance of this paper lies in its contribution to the enrichment of the current scientific discussion about the issue of methodology in digital studies.

\section{Methodology}

It's worth mentioning at this stage that we spent almost ten years studying digital spaces based on online observation, and the analysis of digital content via qualitative data analysis software, namely Atlas.ti. We have conducted our studies since 2011 in network societies, specifically Facebook. The main subject of our analysis was the comments produced by Moroccan Facebook users, or which we call social-electronic interactions. We analyzed about 14.464 comments via the chosen software. We had focused especially on digital political and religious content. However, our discussion will focus on the question of qualitative method in digital space in general, rather than focusing on a specific type of digital content.

Accordingly, what we will represent in this paper is the outcome of our experience as netnographer. That is to say that, we will illustrate the main results which we concluded from our online observation to the digital spaces.

\section{Netnography: the constraints and the challenges of the digital field}

To tackle the research questions, we will try to define the notion of netnography based on the main characteristics which distinguish it from ethnography. Through this overview, we will unveil the different opportunities that netnography provides to scholars and the challenges that they face when they adopt it as a method of research. To address our questions, We will focus on five basic elements which are:

- Intermittent engagement

- Digital Transparency

- Virtual interviewee paradox

- Interpretation applied in the digital space

- Information flows and the limitation of the research scope.

Considering the elements illustrated above, we can notice that many of them constitute common points between ethnography and netnography. There is a dialectic relationship between them, like the relation between the branch and the origin. Hence, we will try in this second part of our paper to clarify these elements by focusing on the special features that distinguish each one of them. 


\subsection{Intermittent engagement}

If immersion in the field is one of the main characteristics of traditional ethnography, the same thing is to be said about netnography. The netnographer needs to immerse himself in his virtual field of study to observe what happens inside it and to gather the appropriate data. However, netnography has its specificity in terms of immersion, and which we could understand in the light of the researched population specificity. In the netnographic studies, the researcher deal with a virtual community, which has transient existence. There are always departures who leave the digital society and new entrants who join it. We witness, over time, a collective process of contents production. Individuals who generate and recreate unlimited digital content and shaping through their electronic activities the structure of the virtual world. To adapt the method with these specificities, the netnographer find himself compelled to opt for an «intermittent engagement» $\left[{ }^{10}\right]$.

The intermittent engagement means, in this context, that the presence of the researcher in his field of work is temporary. He engages in it for a bit to observe and gather the data and leaves it for a bit to immerse himself in the physical world to continue his ordinary life. Then, he rejoins it again for a new phase of observation and leaves it for another time, and so on.

We can say that the researcher's presence itself becomes transient like the entities which constitute the object of his study. Hence, intermittent engagement refers to a specific type of immersion that is in between. The researcher constantly moves, on the same day or in the same hour, between two different spaces, one is physical, and the other is virtual. And that is one of the main characteristics which differs netnography from ethnography.

\subsection{Digital Transparency}

The process of socio-electronic interactions and the automated data documentation resulted from these interactions make digital platforms a « living archive » $\left[{ }^{11}\right]$, dynamic and open, where the digital data is stored continuously, at the moment when the internet user produces it. This characteristic constitutes another feature that distinguishes netnography from ethnography, that is to say, the "immediate access to data " $\left[{ }^{12}\right]$. This feature presents an extension of another, which has constituted one of the primary determinants that reflects the specificity of the digital space logic, namely visibility.

It is a fact that the digital space has been defined, from the very beginning, as a place of transparency. The virtual rooms of chatting, the different platforms of social networks, like Myspace, Facebook, Instagram, and so forth, become the new favourite places for selfexposing, exhibitionism, and revealing experiences, in all its forms, and all its levels. Although This may be true, the notion of digital visibility is still problematic and puzzling. It represents an incomplete system of transparency. When we consider it closely, we can see how internet users employ digital visibility as a strategy for concealment and disguise. They display some sides of their personality and hide other sides in a way that makes the process of self-expressing a selective act. 


\subsection{Virtual interviewee paradox}

The digital traces produced in the virtual communities is the main subject of the netnographer' research work. This means that the producer of those traces participates in a research without his knowledge nor his approval. Moreover, the process of digital content production, in this case, is not guided by any research question.

The paradox raises here concerns the validity of using the term of the interviewee: is it appropriate to apply it to describe the content producer even though he does not negotiate with the researcher any protocol of research, and does not give him his approval about it? This question leads us to another side of the paradox, which concerns research ethics in the digital spaces.

Henceforth, instead of using the term interviewee singular, we prefer to use the term supposed interviewee to deal with the constraints arising from that paradox. The attribute supposed used here, in our view, reflects the specificity of digital presence, and also reflects the specificity of the participation in research which is (in this case) just supposed participation. This is because the individual who is concerned by it, when he involves in the process of digital content production, he does it not as reply to the researcher demand, but just for the pleasure of sharing and interacting with his internet users pairs.

\subsection{Interpretation applied in the digital space}

It appears from what we have mentioned above that the digital space is a place for meanings making to those who use it, to interchange ideas and believes. This is also true for the researcher who works on it, and who tries to guess and reproduce the meaning based on what is published on the digital platforms.

However, the main problem that the netnographer could face in this case is overinterpretation. This is because of the researcher tendency to reduce the observed cases studies, or because of the excessive search for harmony, or the desire for generalization $\left[{ }^{13}\right]$. This overinterpretation could become a problematic issue in the phase of data analysis, taking into account the fact of the high amount of quotation which characterizes the digital content produced by internet users $\left[{ }^{14}\right]$.

The problem that we raise here consists of the fact that quotations lacked, mostly, citation, which means that the process of content production, in a similar case, is just a mere haking of intellectual property, intentionally or unintentionally. So, the result would be an intermingling between speakers' voices, which would lead to a misinterpretation if the researcher did not pay attention to this overlapping between the internet users' discourses and those of other speakers (writers, scholars, religious leaders, scientists...).

Therefore, the netnographer should be aware of the boundaries that separate between the different types of voices included in a single digital content produced by one internet user. In other words, he should constantly be mindful that intertextuality is one of the main characteristics of digital content. Thus, any interpretation of that content must take this fact into account to avoid misinterpretation.

\subsection{Information flows and the limitation of the research scope}

If information flow is a substantial element in any definition of the internet and its mode of functioning, the opportunities that this element offers to social sciences research are as 
much as the methodological questions it raises. The main question that the netnographer asks when he gets to the fieldwork is how he could limit the research scope?

We can justify the necessity of the research scope limitation by the internal dynamics of digital space, which leads to a continuing change in its structure. For this reason, the exploratory phase appears to be very important to deal appropriately with this issue. Therefore, the netnographer should devote this phase to explore the field of research closely and to define the sample that he will study.

If the exploratory phase will enable the researcher to scrutinize his research question, this type of scrutiny, interchangeably, will enable him to limit the scope of observation, and its components, both quantitatively and qualitatively. Accordingly, if there is an absence of this kind of limitation, the netnographer would spend, vainly, a long time and a considerable effort without a valuable result.

\section{Conclusion}

In short, we can say that netnography has been the leading method for studying the new communities of the digital era. However, this practice does not constitute a genuine approach that has no common ground with the traditional methods of qualitative research. If the digital society has become an extension of physical society, netnography has also become the upgraded and modified version of ethnography. The netnographer derives the basic principles of his method from the ethnographic traditions, but his work is an ongoing attempt to adopt it and develop it, to fit with the digital space and its specificity.

\section{References}

1. S. Reeves, A. Kuper, B. D. Hodges, Qualitative Research Methodologies: Ethnography BMJ, 337, 512 (Aug. 30, 2008), Retrieved (06/09/2020) from: Doi:10.1136/BMJ.a1020

2. H. Rheingold, The Virtual Community, Whole Earth Review, Winter, 61(1987); H. Rheingold, The virtual community: Homesteading on the electronic frontier. MIT Press, 50-56 (2000); H. Rheingold, Virtual communities -exchanging ideas through Computer bulletin boards, Journal of Virtual Worlds Research, Vol.1 Virtual communities 2, Introductory remarks by Howard Rheingold, p.1-5 (April 2008), Retrieve(08/09/2020) from: https://bit.ly/3f1FsED

3. J. G. Palfrey \& U. Gasser, Born Digital: Understanding the First Generation of Digital Natives, Philadelphia: RHYW, vii (2011)

4. C. J. Carpenter \& E. L., Spottswood, Exploring romantic relationships on social networking sites using the self-expansion model. Computers in Human Behavior, 29, 1531-1537 (2013) Retrieved (08/09/2020) from: https://doi.org/10.1016/j.chb.2013.01.021; T. Stenger \& A. Coutant, «Un monde d'amis? Une ébauche de typologie sur les réseaux socionumériques », in Connexions, communication numérique et lien social, Belgique: Presses Universitaires de Namur, 213 (2012)

5. R. Rogers, Digital Methods (Cambridge; London: The MIT Press, 2013).

6. C. M. Hine, Virtual Methods: Issues in Social Research on the Internet (Oxford: Berg Publishers, 35-50, 2005)

7. N. Marres, The Redistribution of Methods: on Intervention in Digital Social 
Research, Broadly Conceived, The Sociological Review, vol. 60, no. 1, 149-150 (2012)

8. J. Jouet \& C. Le Caroff, L'observation ethnographique en ligne, in Manuel $D$ 'analyse de Web,éd. Christine Barat, Collection Sciences Humaines et Sociales, 147 (Paris: Armand Colin, 2013)

9. M. Dhiraj, Emergent digital ethnographic methods for social research. Handbook of emergent technologies in social research,158-179 (2011)

10. C. M. Hine, Virtual Ethnography, (Thousand Oaks, CA: Sage Publications Ltd, 2000; Christine. M. Hine, Ethnographies of Online Communities and Social Media: Modes, Varieties, Affordance. in The SAGE handbook of online research methods,éds., Nigel G. Fielding et al., 66-71 (Sage, 2017)

11. C. Barats, et al., Approches textométriques du web: corpus et outils, in Manuel D'analyse de Web,éd. Christine Barat, Collection Sciences Humaines et Sociales, 105 (Paris: Armand Colin, 2013)

12. J. Jouet \& C. Le Caroff, L'observation ethnographique en ligne, in Manuel D'analyse de Web, éd. Christine Barat, Collection Sciences Humaines et Sociales, 148 (Paris: Armand Colin, 2013)

13. S. Heas \& V. Poutrain, les méthodes d'enquête qualitative sur Internet, Ethnographiques, org, $n^{\circ} 4,1-8$. (2003), Retrieved (28/09/2020) from: https://bit.ly/3dHM9Ka

14. S. Heas \& V. Poutrain, «les méthodes d'enquête qualitative sur Internet», op.cit. 